\title{
丛枝菌根真菌对不同性别组合模式下青杨雌雄植 株根系生长的影响
}

高文童 张春艳 $^{1,2}$ 董廷发 ${ }^{1,2}$ 胥 晓 $1,2 *$

${ }^{1}$ 西华师范大学生命科学学院, 四川南充 637009 ; $^{2}$ 西华师范大学西南野生动植物资源保护教育部重点实验室, 四川南充 637009

摘 要 从枝菌根真菌(AMF)对雌雄异株植物根系生长, 尤其是对邻近生长的不同雌雄个体的影响还鲜有研究。该研究以泥 土:河沙:蛭石体积比为 $1: 1: 1$ 的混合物为培养基质, 分别在雄-雄、雌-雌和雄-雌3种组合栽培模式下对青杨(Populus cathayana) 雌雄幼苗进行接种和不接种摩西球囊霉(Funneliformis mosseae)处理, 通过比较接种AMF与否雌雄植株根系在侵染率、生物 量、形态、碳、氮含量等方面的差异来分析AMF对青杨雌雄幼苗根系生长发育的影响。结果发现: 与对照组相比, 接种AMF 对3种栽培模式下青杨雌雄植株的侵染率、根干质量、根系形态(除分枝强度、比表面积)和碳、氮含量影响显著。此外, 不同 性别组合模式对青杨雌雄植株的根干质量、根系形态和碳、氮含量影响显著。接种AMF后, 与雌-雌合栽模式下的雌株相比, 雄 -雌合栽模式下雌株的根干质量、氮含量都有不同程度的提高, 根系形态发生改变; 而与雄-雄合栽模式下的雄株相比, 雄-雌 合栽模式下雄株的相应指标出现降低或轻微增加。该研究表明AMF对不同性别组合模式下青杨植株根系生长具有显著促进 作用，尤其是雄-雌合栽模式下AMF接种最有利于雌株根系的生长发育。

关键词 从枝菌根真菌; 青杨; 雌雄异株; 栽培模式; 根系生长

高文童, 张春艳, 董廷发, 胥晓 (2019). 从枝菌根真菌对不同性别组合模式下青杨䧳雄植株根系生长的影响. 植物生态学报, 43, 37-45. DOI: $10.17521 /$ cjpe.2018.0261

\section{Effects of arbuscular mycorrhizal fungi on the root growth of male and female Populus ca- thayana individuals grown under different sexual combination patterns}

GAO Wen-Tong ${ }^{1}$, ZHANG Chun-Yan ${ }^{1,2}$, DONG Ting-Fa ${ }^{1,2}$, and XU Xiao ${ }^{1,2^{*}}$

${ }^{1}$ College of Life Sciences, China West Normal University, Nanchong, Sichuan 637009, China; ${ }^{2}$ Key Laboratory of Southwest China Wildlife Resources Conservation (China West Normal University), Ministry of Education, Nanchong, Sichuan 637009, China

\section{Abstract}

Aims Accumulating evidence suggests that arbuscular mycorrhizal fungi (AMF) can promote the growth of plant roots. However, the effects of AMF on the root growth of dioecious plants, particularly those grown under different sexual combination patterns, remain largely unknown, this study therefore aimed at improving our understanding of the roles of AMF in these systems.

Methods In the present study, homogenized soil (river sand:surface soil:vermiculite $=1: 1: 1$, volume ratio) was used as growth substrate. The Populus cathayana saplings uninoculated and inoculated with AMF under three sex combination patterns (male vs. male, MM; female vs. female, FF; male vs. female, MF) were defined as control (CK) and AMF treatment group, respectively. Subsequently, we compared the differences in colonization rate, root dry mass, root morphology, carbon $(\mathrm{C})$ content and nitrogen $(\mathrm{N})$ content between $\mathrm{CK}$ and AMF treatments under different sexual combination patterns.

Important findings Our results indicated that colonization rate, root dry mass, root morphology (except root branching intensity, specific root surface area) and $\mathrm{C}, \mathrm{N}$ content were remarkably altered upon inoculation with AMF in comparison to uninoculated controls. Furthermore, the sexual combination patterns were shown to significantly affect root dry mass, root morphology and $\mathrm{C}, \mathrm{N}$ content of male and female $P$. cathayana. After inoculation with AMF, root dry mass, root morphology and $\mathrm{N}$ content of female individuals were increased whereas these parameters of males were decreased or slightly increased in inter-sexual groups compared with the respective intra-sexual groups. Collectively, our data demonstrate the growth-promoting effects of AMF on the roots of

收稿日期Received: 2018-10-29 接受日期Accepted: 2019-01-09

基金项目：国家自然科学基金(31370596)。Supported by the National Natural Science Foundation of China (31370596).

* 通信作者Corresponding author (xuxiao_cwnu@163.com) 
$P$. cathayana individuals grown under different sexual combination patterns, and such beneficial effects are most pronounced in females grown under inter-sexual combination patterns.

Key words arbuscular mycorrhizal fungi; Populus cathayana; dioecious; cultivation pattern; root growth

Gao WT, Zhang CY, Dong TF, Xu X (2019). Effects of arbuscular mycorrhizal fungi on the root growth of male and female Populus cathayana individuals grown under different sexual combination patterns. Chinese Journal of Plant Ecology, 43, 37-45. DOI: $10.17521 /$ cjpe.2018.0261

从枝菌根真菌(AMF)是自然生态系统中广泛存在 且能与绝大多数高等植物的根系形成互惠共生体的土 壤真菌(van der Heijden et al., 1998)。它可以扩大宿主 植物根系在土壤中的有效吸收范围，促进宿主植物对 碳、氮、磷、硫、铁、锌、铜、锰、钾等元素的吸收(赵 昕和阎秀峰, 2006; Sharif \& Claassen, 2011; Lehmann \& Rillig, 2015), 提高水分利用率(Smith \& Read, 2010), 提高植株光合效率以及调节叶片气孔开闭(刘婷和唐 明, 2014)等, 促进植物生长, 增加作物产量(刘晓捷等, 2006), 改善作物产品品质(赵青华等, 2014), 增强植物 抗病能力(Smith et al., 2003)和抗逆性(陈志超等, 2008; Chen et al., 2015b)等。随着研究的不断深入, AMF在根 系生长发育中所扮演的角色逐渐引起人们的重视。大 量的文献表明接种AMF能够促进宿主植物根系的生 长发育, 如接种AMF增加了枳(Poncirus trifoliata)的根 系投影面积、表面积、体积和总长度(邹英宁等, 2014); 干旱胁迫下接种 $\mathrm{AMF}$ 显著增加了小鞍叶羊蹄甲 (Bauhinia faberi var. microphylla)幼苗的总根长、根表 面积、根分枝数和根尖数(张亚敏等, 2017); 常温条件 下接种 $\mathrm{AMF}$ 能增加丰水月季 (Rosa hybrida) 和菊花 (Chrysanthemum morifolium) 的根系长度(孔佩佩, 2011); 白车轴草(Trifolium repens)在接种沾屑多样狍囊霉 (Diversispora spurca)、地表球囊霉(Glomus versiforme) 和隐类球囊霉 (Paraglomus occultum)后植株的根干质 量、长度、投影面积、表面积、体积、根尖数、分枝 数和交叉数均得到提高(吴强盛等, 2014)。然而, 上述 研究多集中在雌雄同株植物中而很少涉及雌雄异株植 物。

相关研究表明, 在 30 多万种被子植物中还存在约 6\%的雌雄异株植物(Renner, 2014), 由于该类植物对自 然界长期适应性进化以及雌雄个体对资源的需求和分 配的不同, 从而导致雌雄植株对环境的适应以及个体 间的竞争和合作能力出现差异(Xu et al., 2008; 杨鹏和 胥晓, 2012; 黄科朝等, 2014)。如Lindera melissifolia在 雄- 雌合栽时具有相同的竞争能力(Hawkins et al., 2009), Distichlis spicata在同性合栽时地下竞争能力更
弱, 而桑(Morus alba) 在雄-雄合栽时的竞争能力更强 (Rogers \& Eppley, 2012; 朱娟等, 2016), 青杨(Populus cathayana)雌株在水分充足时竞争能力比雄株强而在 干旱胁迫下则相反(Chen et al., 2014)。此外, 低氮环境 下青杨在雄-雌合栽时的雌株比同性合栽下的雌株具 有更高的根干质量(Chen et al., 2015a), 桑在雄-雌合栽 模式下相互促进并具有较高的总生物量(朱娟等, 2016; 竺诗慧等, 2016)等。虽然上述研究证实了雌雄异株植 物个体在不同雌雄组合模式下表现出了不一致的竞争 或互利现象, 但均未深入揭示其引起差异的原因。由 于自然界中的雌雄异株植物种群的性别比例总体趋近 于1:1 (王志锋等, 2011), 雌雄个体可以通过根系间的 AMF相互作用(Bonfante \& Genre, 2010; Wu et al., 2018)。因此, 我们推测 AMF可能是引起不同性别组合 模式下雌雄植株生长出现差异的原因之一。然而, 相 关的研究并未见报道。

青杨属于杨柳科杨属(Populus), 是我国常见的雌 雄异株植物。该树种由于具有生长快、存活率高、适 应性强等特点, 是近年来雌雄异株植物研究的常用材 料, 也是AMF营养型树种(宋福强, 2002)。目前, 关于 接种AMF对青杨的影响主要集中在抗旱性(李朕, 2017) 和对重金属的吸附能力(胡相伟, 2016)方面, 而关于接 种AMF对不同性别组合栽培模式下雌雄植株根系影 响的研究未见报道。因此, 本研究以青杨扞插苗为试 验材料, 分别在雄-雄、雌-䧳和雄-雌3 种组合的栽培模 式下对青杨雌雄幼苗进行接种和不接种摩西球囊霉 (Funneliformis mosseae) 处理, 通过比较接种AMF与否 雌雄植株根系的侵染率、生物量、形态、碳氮含量等 在不同性别组合栽模式下的差异, 揭示了AMF对不同 性别组合栽培模式下的青杨根系发育的影响。研究结 果可为青杨的科学栽培提供理论参考。

\section{1 材料和方法}

\section{1 实验材料和生长环境}

实验地点位于四川省南充市西华师范大学试验地 $\left(106.07^{\circ} \mathrm{E}, 30.80^{\circ} \mathrm{N}\right.$, 海拔276 m)。该地区属亚热带季 
风性湿润气候, 年平均气温、降水量、日照时间分别 为 $16.8{ }^{\circ} \mathrm{C} 、 1065 \mathrm{~mm} 、 1980 \mathrm{~h}$ (罗培和周申立, 2007)。 2017年3月从试验地的青杨成树(引种自青海大通)上 采集一年生枝条进行扞插(雌雄各50根扦插条)。扞插 所用的基质为泥土、河沙、蛭石体积比 1:1:1的混合物, 于 $100{ }^{\circ} \mathrm{C}$ 蒸汽灭菌 $2 \mathrm{~h}$ 两次以消除AMF的繁殖体和其 他微生物。在扞插之前将枝条用 $70 \%$ 酒精消毒, 并用蒸 馏水漂洗, 最后放入生根粉溶液中浸泡约 $15 \mathrm{~s}$ 后进行 扞插。待扞插条发芽生长 60 天后, 选取长短、粗细、 健康状况一致的 84 株幼苗(雌雄各42株)移栽到长宽高 分别为 $40 \mathrm{~cm} \times 20 \mathrm{~cm} \times 30 \mathrm{~cm}$ 的玻璃缸中(分别按雄雄, 雌-䧳, 雄-此组合栽培)。实验中的玻璃缸内部装置 与Johansen和Jensen (1996)的类似。在玻璃缸中间放置 两块厚 $0.25 \mathrm{~cm}$ 的多孔有机玻璃板和一张单个孔径为 $37 \mu \mathrm{m}$ 的尼龙网(尼龙网放置在两个玻璃板之间)将容 器分割为两个室。该结构的目的是防止根系穿过, 但 允许菌丝相连(参考He et al., 2004)(图1)。

\section{2 实验设计}

实验采用双因素完全随机设计。2种接种处理：接 种或不接种摩西球囊霉, 3 种性别组合: 雄-雄、雌-䧳、 雄-雌。在接种处理组中每一株幼苗接种 $10 \mathrm{~g}$ 菌剂(接种 剂来自北京市农林科学院植物营养与资源研究所, 包 括纯培养物的基质、根系、狍子以及外生菌丝), 未接 种处理组中每一株幼苗接种进行蒸汽灭菌后的菌剂 10 $\mathrm{g}$, 并施加 $10 \mathrm{~mL}$ 不含 $\mathrm{AMF}$ 的接种剂滤液。以没有接种 菌剂的 3 种性别组合为对照组, 以接种菌剂的 3 种性别 组合为接种组, 总共 6 种组合, 每种组合 7 个重复。

\section{3 测定指标和方法}

\subsection{1 根系形态、生物量、碳、氮含量的测定} 实验处理约 180 天后(一个生长季), 于 2017 年9月

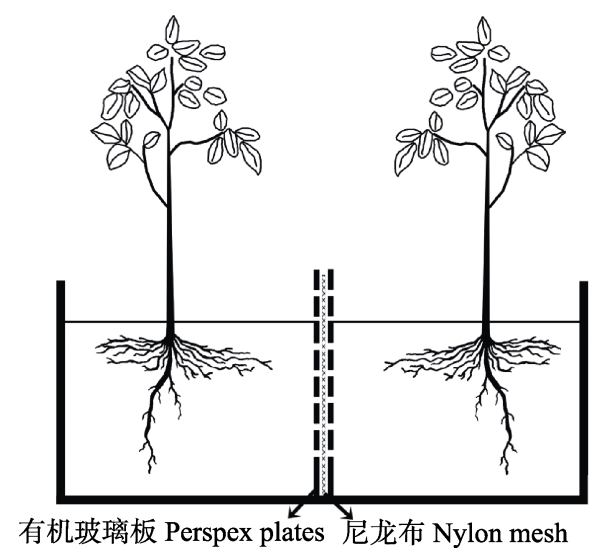

图1 不同性别合栽模式示意图, 每盒含两株幼苗。

Fig. 1 Schematic diagram of mixed-sexes plantation designs, each with two seedlings.
对不同处理组的青杨雌雄幼苗进行采收，从根系 上选取 2-3 个具有代表性的侧枝用根系分析系统 (WinRHIZO, Regents Instruments, Quebec, Canada)进 行扫描, 并测量各株幼苗的总根长、根尖数, 计算分枝 强度、比根长和比表面积。最后将收集的根系放在恒 温干燥箱中 $70{ }^{\circ} \mathrm{C}, 48 \mathrm{~h}$ 烘干至恒质量, 随后用电子天 平称量根系总干质量。最后使用碳氮分析仪(Vario TOC, Elementar Company, Hanau, German)测量根系的 碳、氮含量。

\subsection{2 根系侵染率的测定}

将每种组合下的植株 (7个重复)根系分别洗净后 保存在FAA固定液中, 固定完成后每个植物根系样品 选择至少 100 段直径小于 $1 \mathrm{~mm}$, 长度约 $1 \mathrm{~cm}$ 的新鲜根 段放在 $10 \%$ 的 $\mathrm{KOH}$ 溶液中 $90{ }^{\circ} \mathrm{C}$ 水浴加热 $1 \mathrm{~h}$, 待加热 结束后放入碱性双氧水中进行脱色, 而后取出根系用 墨水和醋(95\%醋和5\%墨水)进行染色，随后用酸化的 水冲洗根段数次(Vierheilig et al., 2010), 最后随机选 取 70 个根段整齐排列在载玻片上用显微镜进行观测。 根据McGonigle等(1990)的方法用以下公式计算菌根 侵染率:

菌根侵染率 $(\%)=$ 菌根根段 $/$ 观察的总根段数 $\times$ $100 \%$

\section{4 数据分析和处理}

采用SPSS 19.0进行数据分析。分析前对数据进行 方差齐性检验, 不符合方差齐性时对数据进行对数转 换。组合、接种及其交互作用的评价采用双因素方差 分析, 组间平均值的比较采用Duncan's多重比较。显著 性水平设定为 $\alpha=0.05$ 。

\section{2 结果和分析}

\section{1 青杨雌雄植株侵染率的差异}

由图 $2 \mathrm{~A}$ 可见, 接种 $\mathrm{AMF}$ 显著提高了 3 种栽培模式 下青杨雌雄植株的菌根侵染率 $(p<0.001)$, 尤其是雄雌合栽模式下的雌株菌根侵染率与对照相比增加了 14.3倍。不同栽培模式对青杨雌雄植株的菌根侵染率 无显著影响，但接种AMF后导致雄-雌合栽模式下的 雌株菌根侵染率显著高于雄株。

\section{2 青杨雌雄植株根干质量的差异}

由图2B可见, 与对照组相比, 接种AMF显著增加 了不同性别组合栽培模式下青杨雌雄植株的根干质量 $(p<0.001)$, 其中雄-雄合栽模式下雄株根干质量增加 
最多，是未接种的1.7倍; 不同栽培模式对青杨植株的 根干质量也有显著影响 $(p<0.001)$ 。未接种AMF时, 雄 -雌合栽模式下的雌株根干质量高于雌-雌合栽中的雌 株, 但雄株无显著差异; 接种AMF处理下, 不同合栽 模式下相应性别植株根干质量均无显著差异。此外, 在3种栽培模式中雌株的根干质量均显著高于雄株。

\section{3 青杨雌雄植株根系形态的差异}

由表1知，与对照组相比，接种AMF对不同性别
组合栽培模式下青杨植株根系的比根长、总根长和根 尖数影响显著 $(p<0.05)$, 其中雄-雌合栽模式下雄株的 总根长以及雌株的比根长和根尖数增加最多, 而雄-雄 合栽模式下青杨雄株的比根长显著下降; 不同栽培模 式对青杨植株的分枝强度、比表面积、比根长、总根 长和根尖数均有显著影响 $(p<0.05)$ 。在对照组中雄雄合栽模式下雄株的比表面积和比根长显著大于雄雌合栽模式下的雄株, 而分枝强度则相反。雌-雌合栽
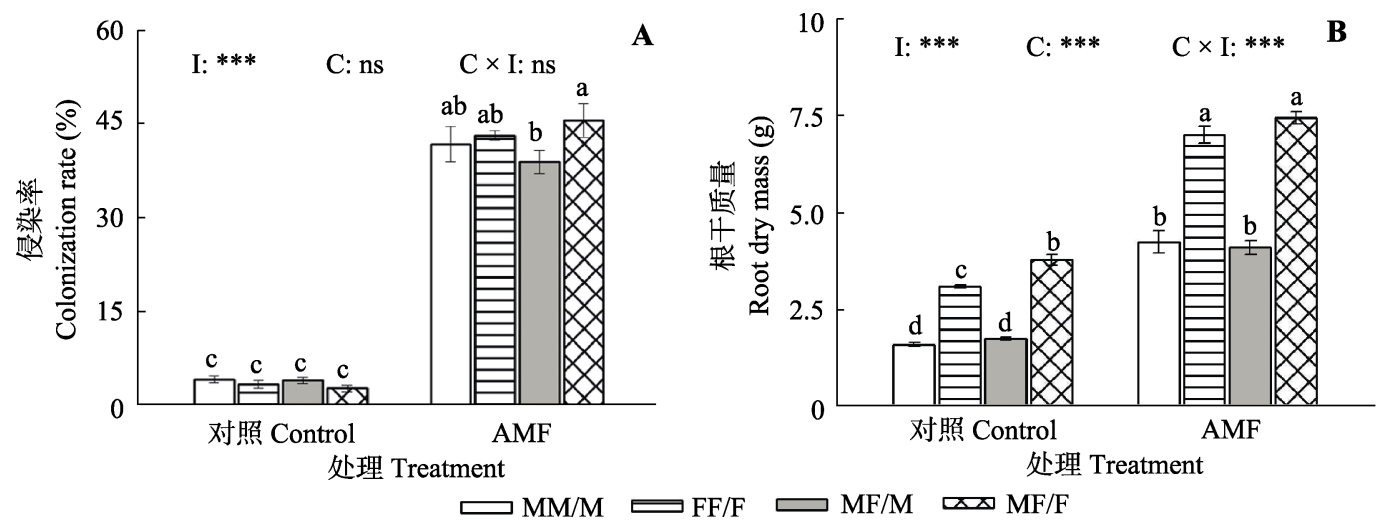

图2 接种从枝菌根真菌(AMF)对不同栽培模式下青杨雌雄植株菌根侵染率和根干质量的影响(平均值 \pm 标准误差, $n=7$ )。柱形 上方不同小写字母表示相应处理之间差异显著(采用Duncan's多重比较, $p<0.05$ )。C, 组合效应; I, 接种效应; C $\times \mathrm{I}$, 组合与接 种交互效应。ns, 没有显著差异; ***, $p<0.001$ 。 MM/M, 性别内组合下的雄株; FF/F, 性别内组合下的雌株; MF/M, 性别间组 合下的雄株; MF/F，性别间组合下的雌株。

Fig. 2 Effects of arbuscular mycorrhizal fungi (AMF) on the colonization rate and root dry mass of male and female Populus cathayana individuals grown under different sexual combination patterns (mean $\pm S E, n=7$ ). Different lowercase letters above the columns represent significant differences between corresponding treatments according to Duncan's multiple range test $(p<0.05)$. C, combination pattern effect; $\mathrm{I}$, inoculation effect; $\mathrm{C} \times \mathrm{I}$, combination pattern and inoculation interaction effect. ns, not significant; ***, $p<0.001 . \mathrm{MM} / \mathrm{M}$, males in the intra-sexual combination; $\mathrm{FF} / \mathrm{F}$, females in the intra-sexual combination; MF/M, males in the inter-sexual combination; $\mathrm{MF} / \mathrm{F}$, females in the inter-sexual combination.

表1 接种从枝菌根真菌(AMF)对不同栽培模式下青杨雌雄植株根系形态的影响(平均值土标准误差, $n=7$ )

Table 1 Effects of arbuscular mycorrhizal fungi (AMF) on the root morphology of male and female Populus cathayana individuals grown under different sexual combination patterns (mean $\pm S E, n=7$ )

\begin{tabular}{|c|c|c|c|c|c|c|}
\hline $\begin{array}{l}\text { 组别 } \\
\text { Group }\end{array}$ & $\begin{array}{l}\text { 组合 } \\
\text { Combination pattern }\end{array}$ & $\begin{array}{c}\text { 分枝强度 } \\
\text { Root branching } \\
\text { intensity }\left(\times 10^{2}\right)\end{array}$ & $\begin{array}{c}\text { 比表面积 } \\
\text { Specific root } \\
\text { surface area }\left(\times 10^{2}\right)\end{array}$ & $\begin{array}{c}\text { 比根长 } \\
\text { Specific root } \\
\text { length }\left(\times 10^{3}\right)\end{array}$ & $\begin{array}{l}\text { 总根长 } \\
\text { Total root length } \\
\left(\mathrm{cm} \times 10^{3}\right)\end{array}$ & $\begin{array}{c}\text { 根尖数 } \\
\text { Root tips } \\
\text { number }\left(\times 10^{3}\right)\end{array}$ \\
\hline 对照 & 雄雄/雄 $\mathrm{MM} / \mathrm{M}$ & $5.01 \pm 0.34^{b}$ & $3.49 \pm 0.49^{\mathrm{ab}}$ & $5.97 \pm 0.49^{\mathrm{b}}$ & $25.58 \pm 2.23^{\mathrm{ef}}$ & $20.97 \pm 1.69^{\mathrm{cd}}$ \\
\hline \multirow[t]{3}{*}{ Control } & 雌雌/雌 FF/F & $4.26 \pm 0.37^{\mathrm{b}}$ & $2.99 \pm 0.24^{\mathrm{bc}}$ & $4.58 \pm 0.34^{\mathrm{cd}}$ & $33.08 \pm 2.39^{\mathrm{de}}$ & $19.09 \pm 1.84^{\mathrm{d}}$ \\
\hline & 雄雌/雄 MF/M & $7.81 \pm 0.52^{\mathrm{a}}$ & $1.75 \pm 0.27^{\mathrm{d}}$ & $3.80 \pm 0.28^{\mathrm{d}}$ & $14.81 \pm 1.25^{\mathrm{f}}$ & $17.71 \pm 1.37^{\mathrm{d}}$ \\
\hline & 雄雌/雌 MF/F & $7.83 \pm 0.29^{\mathrm{a}}$ & $2.70 \pm 0.44^{\mathrm{c}}$ & $5.04 \pm 0.54^{\mathrm{bcd}}$ & $42.46 \pm 4.38^{\mathrm{cd}}$ & $18.33 \pm 1.50^{\mathrm{d}}$ \\
\hline \multirow[t]{7}{*}{$\mathrm{AMF}$} & 雄雄/雄 $\mathrm{MM} / \mathrm{M}$ & $4.46 \pm 0.30^{\mathrm{b}}$ & $2.14 \pm 0.20^{\mathrm{cd}}$ & $4.09 \pm 0.18^{\mathrm{d}}$ & $58.47 \pm 4.25^{\mathrm{c}}$ & $25.66 \pm 1.27^{\mathrm{c}}$ \\
\hline & 雌雌/雌 FF/F & $4.83 \pm 0.34^{b}$ & $3.28 \pm 0.16^{\mathrm{ab}}$ & $5.67 \pm 0.48^{\mathrm{bc}}$ & $105.30 \pm 9.82^{b}$ & $38.47 \pm 1.75^{\mathrm{b}}$ \\
\hline & 雄雌/雄 MF/M & $6.70 \pm 0.53^{\mathrm{a}}$ & $2.89 \pm 0.20^{\mathrm{bc}}$ & $4.99 \pm 0.43^{\mathrm{bcd}}$ & $55.88 \pm 5.66^{\mathrm{c}}$ & $25.95 \pm 1.51^{\mathrm{c}}$ \\
\hline & 雄雌/雌 MF/F & $6.88 \pm 0.31^{\mathrm{a}}$ & $3.99 \pm 0.31^{\mathrm{a}}$ & $7.29 \pm 0.52^{\mathrm{a}}$ & $137.96 \pm 8.17^{\mathrm{a}}$ & $51.88 \pm 3.42^{\mathrm{a}}$ \\
\hline & $p>F_{\mathrm{I}}$ & $0.069^{\mathrm{ns}}$ & $0.126^{\mathrm{ns}}$ & $0.033^{*}$ & $<0.001^{* * *}$ & $<0.001^{* * *}$ \\
\hline & $p>F_{\mathrm{C}}$ & $<0.001^{* * *}$ & $0.011^{*}$ & $0.002^{* *}$ & $<0.001^{* * *}$ & $<0.001^{* * *}$ \\
\hline & $p>F_{\mathrm{C} \times \mathrm{I}}$ & $0.142^{\mathrm{ns}}$ & $<0.001^{* * *}$ & $<0.001^{* * *}$ & $<0.001^{* * *}$ & $<0.001^{* * *}$ \\
\hline
\end{tabular}

同列均值后不同小写字母表示相应处理之间差异显著(采用Duncan's多重比较, $p<0.05$ )。C, 组合效应; I, 接种效应; $\mathrm{C} \times \mathrm{I}$, 组合与接种交互效应。ns, 没 有显著差异; ***, $p<0.001$ 。 MM/M, 性别内组合下的雄株; FF/F, 性别内组合下的雌株; MF/M, 性别间组合下的雄株; MF/F, 性别间组合下的雌株。

Different lowercase letters following the means in the same column represent significant differences between corresponding treatments according to Duncan's multiple range test $(p<0.05)$. C, combination pattern effect; I, inoculation effect; $\mathrm{C} \times \mathrm{I}$, combination pattern and inoculation interaction effect. ns, not significant; $*_{* *}, p<0.001 . \mathrm{MM} / \mathrm{M}$, males in the intra-sexual combination; $\mathrm{FF} / \mathrm{F}$, females in the intra-sexual combination; MF/M, males in the inter-sexual combination; $\mathrm{MF} / \mathrm{F}$, females in the inter-sexual combination.

www.plant-ecology.com 
模式下雌株的分枝强度显著小于雄-雌合栽模式下的 雌株。在接种AMF后, 雄-雄合栽模式下雄株的分枝强 度显著小于雄-雌合栽下的雄株, 而雌-雌合栽模式下 雌株的分枝强度、比根长、总根长和根尖数均显著小 于雄-雌合栽模式下的雌株。此外, 由图3可见, 与对照 相比, 接种AMF的青杨植株, 尤其是雄-雌合栽模式下 的䧳株的根系构型明显优于未接种的植株。

\section{4 青杨雌雄植株根系碳、氮含量的差异}

由图4可见, 与对照组相比, 接种 $\mathrm{AMF}$ 处理对 3 种 性别栽培模式下青杨雌雄植株的碳、氮含量影响显著 $(p<0.001$ 和 $p<0.01)$, 接种AMF后雌-雌合栽模式下雌
株的碳、氮含量分别增加了 $6 \%$ 和 $49 \%$; 不同栽培模式 对青杨雌雄植株碳、氮含量也有显著影响 $(p<0.05$ 和 $p$ $<0.001)$ 。在对照组中雌-䧳合栽模式下的雌株氮含量 显著低于雄-䧳合栽模式下的雌株, 而在接种处理组中 雄-雄合栽模式下雄株的氮含量显著高于雄-雌合栽模 式下的雄株。

\section{3 讨论}

前人的研究证实了接种AMF会提高植株根系的 菌根侵染率, 但很少有人关注接种AMF后雌雄植株的 侵染率差异问题。尽管由于接种剂的类型或剂量的

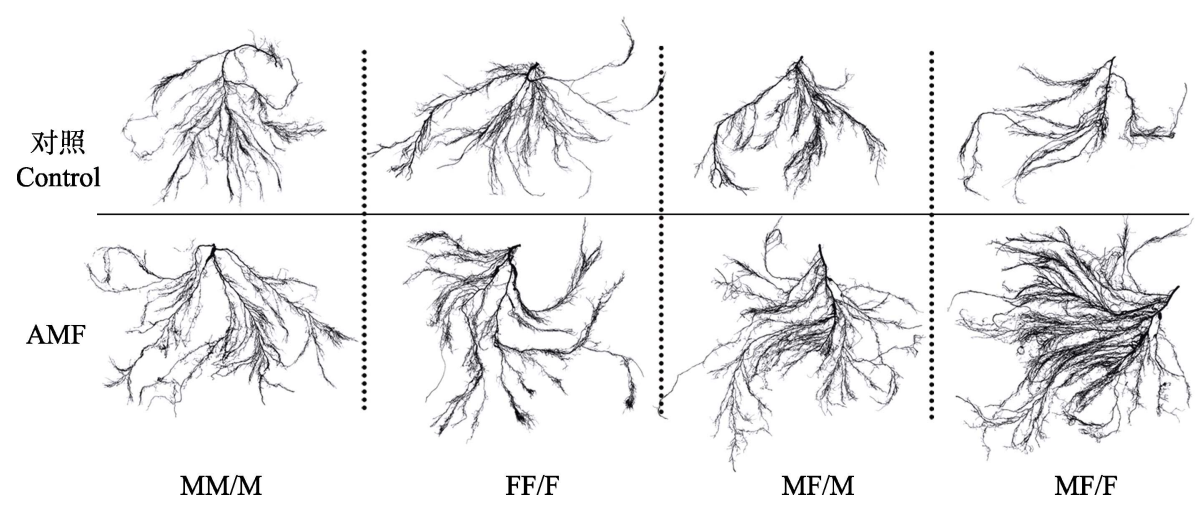

图3 接种从枝菌根真菌(AMF)对不同栽培模式下青杨雌雄植株根系构型的影响。MM/M, 性别内组合下的雄株; FF/F, 性别内 组合下的雌株; MF/M，性别间组合下的雄株; MF/F，性别间组合下的雌株。

Fig. 3 Effects of arbuscular mycorrhizal fungi (AMF) on the root system architecture of male and female Populus cathayana individuals grown under different sexual combination patterns. MM/M, males in the intra-sexual combination; FF/F, females in the intra-sexual combination; MF/M, males in the inter-sexual combination; MF/F, females in the inter-sexual combination.
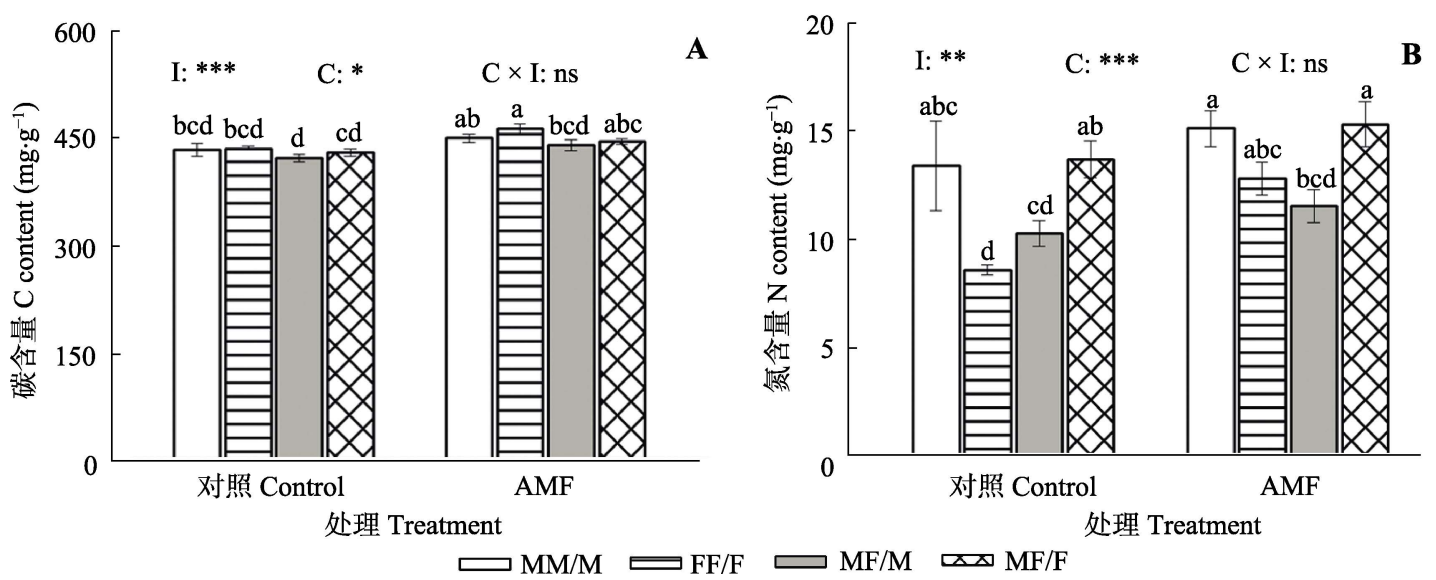

图4 接种从枝菌根真菌(AMF)对不同栽培模式下青杨雌雄植株根系碳和氮的影响(平均值土标准误差, $n=7)$ 。柱形上方不同小 写字母表示相应处理之间差异显著(采用Duncan's多重比较, $p<0.05$ )。C, 组合效应; I, 接种效应; C $\times$ I, 组合与接种交互效应。 $\mathrm{ns}$, 没有显著差异; ***, $p<0.001$ 。 MM/M, 性别内组合下的雄株; FF/F, 性别内组合下的雌株; MF/M, 性别间组合下的雄株; $\mathrm{MF} / \mathrm{F}$ ，性别间组合下的雌株。

Fig. 4 Effects of arbuscular mycorrhizal fungi (AMF) on the $\mathrm{C}$ content and $\mathrm{N}$ content in roots of male and female Populus cathayana individuals grown under different sexual combination patterns (mean $\pm S E, n=7$ ). Different lowercase letters above the columns represent significant differences between corresponding treatments according to Duncan's multiple range test $(p<0.05)$. C, combination pattern effect; I, inoculation effect; $\mathrm{C} \times \mathrm{I}$, combination pattern and inoculation interaction effect. ns, not significant; ***, $p<0.001$. MM/M, males in the intra-sexual combination; FF/F, females in the intra-sexual combination; $\mathrm{MF} / \mathrm{M}$, males in the inter-sexual combination; $\mathrm{MF} / \mathrm{F}$, females in the inter-sexual combination. 
原因, 本研究中青杨雌雄植株的侵染率与 Chen等 (2015b)和Wu等(2016)的研究结果相比偏低, 但研究结 果表明接种AMF不仅显著增加了青杨雌雄植株根系 的侵染率, 而且在雄-䧳合栽模式下青杨雌株的侵染率 显著高于雄株(雌株的侵染率为 $43 \%-46 \%$, 雄株的侵 染率为 $39 \%-42 \%)$ 。由于性别二态性原因, 雌雄植株在 资源需求、生理过程(如气体交换、水分利用和元素吸 收等)、形态发育、生物量积累、抗逆能力以及分布格 局等方面明显不同(Dawson \& Ehleringer, 1993; Renner, 2014; Wu et al., 2015), 这种差异甚至体现在不同性别 合栽模式下雌雄植株对邻株根系的性别识别以及引起 根系分泌物的变化(胥晓, 2016; 曾贞, 2016; 竺诗慧等, 2016)上。根据Graham等(1981)和Buee等(2000)的研究, 根系分泌物的成分和含量差异会影响AMF对寄主植 物的侵染程度。因此, 雄-雌合栽模式下青杨雌雄植株 的侵染率出现差异极可能与雌雄互作后引起根系分泌 物的差异有很大的关系。

此外, 本研究还发现接种AMF后青杨此雄植株根 系的生物量和总根长显著增加, 这与宋福强(2002)对 大青杨(P. ussuriensis) 的研究结果吻合, 二者都证实了 接种AMF可以促进杨属植物根系的生长发育。AMF促 进植物根系生长的原因主要是增加了寄主植物对磷的 吸收(郭晗铃等, 2017), 但近年也发现AMF可以从土壤 有机物(如叶调落物) 中获取氮并转移到寄主植物根中 (Hodge et al., 2001; Leigh et al., 2009), 提高植物利用 氮的能力并促进光合作用, 从而有利于植物的生长 (Krishna et al., 2005)。与此同时, 植株光合速率与光合 能力的提高可以使根系间接获得更多的可溶性糖或淀 粉等碳水化合物, 从而导致根系中碳含量的增加(吉春 龙等, 2010)。与上述结果相一致, 我们也发现了接种 AMF对 3 种栽培模式下青杨雌雄植株根系的碳、氮含 量具有一定的促进作用。然而, 由于实验设计的缺陷, 我们未考虑接种 $\mathrm{AMF}$ 前后雌雄植株根系中磷含量的 变化, 故无法在磷吸收方面提供更多的证据, 还需要 在下一步研究工作中予以验证。

另一方面, 与Chen等(2015)的研究结果类似, 我 们也发现青杨雌雄植株的根质量、根形态以及氮含量 与栽培模式关系密切, 而且还受到AMF的影响。如异 性合栽模式下雌株的根干质量、比表面积、比根长、 总根长和氮含量均显著大于雄株, 反映了雌株在异性 合栽模式下生长更好。其原因可能在于: 一是植株的 根系在生长过程中具有自我识别和性别识别能力, 它
们能通过调节自身根系的生长发育去适应周围其他植 株的根系(胥晓, 2016), 青杨植株在同性组合时会改变 根系的生长, 但在异性组合时却无该现象(Dong et al., 2017)。二是植株的根系分泌物与植株的根系发育密切 相关(曾贞, 2016), 异性植株根系分泌物对雌株的株 高、基径、叶面积和根、茎、叶生物量等具有显著的 促进作用(竺诗慧等, 2016)。三是不同性别的植株因对 资源的需求不同而可能存在互助作用。AMF寄主特异 性很低, 根外菌丝可以成为植株间物质交换的桥梁 (Giovannetti et al., 2004; He et al., 2004), 在雄-雌合栽 模式下的雄株极有可能将自身的氮素通过菌丝转移给 资源需求更高的雌株, 使得雌株和雄株合栽后更有利 于雌株根系的发育, 以维持种群的延续。本实验中根 系的氮含量与Chen等(2017)的研究结果一致, 都表明 在雄-䧳合栽模式下的雌株氮含量高于雌-雌合栽模式, 雄株的氮含量则相反。这虽然验证了我们的假设, 但 仍需开展进一步的研究。

\section{4 结论}

综上所述, 我们以青杨为模式物种, 研究了接种 AMF对不同栽培模式下青杨雌雄植株根系生长发育 的影响。结果表明AMF、不同性别栽培模式以及两者 的交互作用都对青杨雌雄植株的根系生长发育有不同 程度的影响; 接种AMF后, 雄-雌合栽最有利于青杨雌 株根系的生长发育, 这为杨树的优质培育提供了新的 思路。另外, 我们还发现AMF对青杨雌雄植株间的相 互作用有潜在的影响, 这对种群的稳定性和延续可能 具有重要的意义。

\section{参考文献}

Bonfante P, Genre A (2010). Mechanisms underlying beneficial plant-fungus interactions in mycorrhizal symbiosis. Nature Communications, 1, 48. DOI: 10.1038/ncomms1046.

Buee M, Rossignol M, Jauneau A, Ranjeva R, Bécard G (2000). The pre-symbiotic growth of arbuscular mycorrhizal fungi is induced by a branching factor partially purified from plant root exudates. Molecular Plant-Microbe Interactions, 13, 693-698.

Chen J, Dong TF, Duan BL, Korpelainen H, Niinemets Ü, Li CY (2015a). Sexual competition and N supply interactively affect the dimorphism and competiveness of opposite sexes in Populus cathayana. Plant, Cell \& Environment, 38, 1285-1298.

Chen J, Duan BL, Wang M, Korpelainen H, Li CY (2014). Intra- and inter-sexual competition of Populus cathayana 
under different watering regimes. Functional Ecology, 28, 124-136.

Chen J, Han QQ, Duan BL, Korpelainen H, Li CY (2017). Sex-specific competition differently regulates ecophysiological responses and phytoremediation of Populus cathayana under Pb stress. Plant and Soil, 421, 203-218.

Chen LH, Hu XW, Yang WQ, Xu ZF, Zhang DJ, Gao S (2015b). The effects of arbuscular mycorrhizal fungi on sex-specific responses to $\mathrm{Pb}$ pollution in Populus cathayana. Ecotoxicology and Environmental Safety, 113, 460-468.

Chen ZC, Shi ZY, Tian CY, Feng G (2008). Effects of arbuscular mycorrhizal fungi inoculation on growth and nutrient uptake of two ephemeral plants. Journal of Plant Ecology (Chinese Version), 32, 648-653. [陈志超, 石兆 勇, 田长彦, 冯固 (2008). 接种 $\mathrm{AM}$ 真菌对短命植物生 长发育及矿质养分吸收的影响. 植物生态学报, 32 , 648-653.]

Dawson TE, Ehleringer JR (1993). Gender-specific physiology, carbon isotope discrimination, and habitat distribution in boxelder, Acer negundo. Ecology, 74, 798-815.

Dong T, Li J, Liao Y, Liu J, Chen B, Xu X (2017). Rootmediated sex recognition in a dioecious tree. Scientific Reports, 7, 801. DOI: 10.1038/s41598-017-00894-2.

Giovannetti M, Sbrana C, Avio L, Strani P (2004). Patterns of below-ground plant interconnections established by means of arbuscular mycorrhizal networks. New Phytologist, 164, 175-181.

Graham JH, Leonard RT, Menge JA (1981). Membranemediated decrease in root exudation responsible for phorphorus inhibition of vesicular-arbuscular mycorrhiza formation. Plant Physiology, 68, 548-552.

Guo HL, Liu SJ, Xu J, Song SR, Tang JJ, Chen X (2017). Effects of arbuscular mycorrhizal fungi on growth and root traits of dicotyledons plants: A meta analysis. Chinese Journal of Ecology, 36, 1855-1864. [郭晗铃, 刘世俊, 徐 静, 宋书锐, 唐建军, 陈欣 (2017). 丛枝菌根真菌对双 子叶植物生长和根系特征的影响: 整合分析. 生态学杂 志, 36, 1855-1864.]

Hawkins TS, Schiff NM, Leininger TD, Gardiner ES, Devall MS, Hamel PB, Wilson AD, Connor KF (2009). Growth and intraspecific competitive abilities of the dioecious Lindera melissifolia (Lauraceae) in varied flooding regimes. The Journal of the Torrey Botanical Society, 136, 91-101.

He XH, Critchley C, Ng H, Bledsoe CS (2004). Reciprocal N $\left({ }^{15} \mathrm{NH}_{4}^{+}\right.$or $\left.{ }^{15} \mathrm{NO}_{3}^{-}\right)$transfer between nonN $\mathrm{N}_{2}$-fixing Eucalyptus maculata and $\mathrm{N}_{2}$-fixing Casuarina cunninghamiana linked by the ectomycorrhizal fungus Pisolithus sp. New Phytologist, 163, 629-640.

Hodge A, Campbell CD, Fitter AH (2001). An arbuscular mycorrhizal fungus accelerates decomposition and acquires nitrogen directly from organic material. Nature, 413, 297.

Hu XW (2016). Effect of Arbuscular Mycorrhizal Fungi on Sex-specific Responses of Physiological and Biochemical Characteristics of Populus cathayana under Pb Pollution. Master degree dissertation, Sichuan Agricultural University, Chengdu. [胡相伟 (2016). 丛枝菌根对受铅胁迫的 雌雄青杨(Populus cathayana)生理生化特性的影响. 硕 士学位论文, 四川农业大学, 成都.]

Huang KC, Xu X, Li XF, He JD, Yang YX, Huan HH (2014). Gender-specific characteristics of tree-ring growth and differential responses to climate change in the dioecious tree Populus cathayana in Xiaowutai Mountains, China. Chinese Journal of Plant Ecology, 38, 270-280. [黄科朝, 胥晓, 李霄峰, 贺俊东, 杨延霞, 狍慧慧 (2014). 小五 台山青杨雌雄植株树轮生长特性及其对气候变化的响 应差异. 植物生态学报, 38, 270-280.]

Ji CL, Tian MM, Ma JF, Jin HR (2010). Advances in the researches on the effects of arbuscular mycorrhizal fungi on plant nutrition metabolism and growth effects. Journal of Zhejiang Normal University (Natural Sciences), 33, 303-309. [吉春龙, 田萌萌, 马继芳, 金海如 (2010). 丛 枝菌根真菌对植物营养代谢与生长影响的研究进展. 浙江师范大学学报(自然科学版), 33, 303-309.]

Johansen A, Jensen ES (1996). Transfer of N and P from intact or decomposing roots of pea to barley interconnected by an arbuscular mycorrhizal fungus. Soil Biology \& Biochemistry, 28, 73-81.

Kong PP (2011). Effects of Arbuscular Mycorrhizal Fungi on Growth and Temperature Tolerance of Rosa hybrid and Chrysanthemum morifolium. Master degree dissertation, Academy of Agricultural Sciences, Beijing. [孔佩佩 (2011). 丛枝菌根真菌对切花月季和切花菊生长及温度 胁迫耐受性的影响. 硕士学位论文, 中国农业科学院, 北京.]

Krishna H, Singh SK, Sharma RR, Khawale RN, Grover M, Patel VB (2005). Biochemical changes in micropropagated grape (Vitis vinifera L.) plantlets due to arbuscularmycorrhizal fungi (AMF) inoculation during ex vitro acclimatization. Scientia Horticulturae, 106, 554-567.

Lehmann A, Rillig MC (2015). Arbuscular mycorrhizal contribution to copper, manganese and iron nutrient concentrations in crops-A meta-analysis. Soil Biology \& Biochemistry, 81, 147-158.

Leigh J, Hodge A, Fitter AH (2009). Arbuscular mycorrhizal fungi can transfer substantial amounts of nitrogen to their host plant from organic material. New Phytologist, 181, 199-207.

Li Z (2017). Influence of Arbuscular Mycorrhiza Fungi (AMF) Inoculation on Drought Tolerance of Populus cathayana Rehder Males and Females. PhD dissertation, Northwest A\&F University, Yangling, Shaanxi. [李朕 (2017). 丛枝 菌根真菌(AMF)提高青杨雌雄株抗旱性的研究. 博士学 
位论文，西北农林科技大学，陕西杨凌.]

Liu T, Tang M (2014). Effects of arbuscular mycorrhizal fungi on growth and anatomical properties of stomata andxylem in poplars. Chinese Journal of Plant Ecology, 38, 1001-1007. [刘婷, 唐明 (2014). 丛枝菌根真菌对杨树 生长、气孔和木质部微观结构的影响. 植物生态学报, 38, 1001-1007.]

Liu XJ, Zeng M, Du JB, Ren Z (2006). Effects of AMF on the growth and mineral nutrition of grape cuttings. Journal of Southwest Agricultural University (Natural Science), 28, 286-289. [刘晓捷，曾明，杜建斌，任争 (2006). AMF对 葡萄扦插苗矿质营养及生长的影响. 西南大学学报(自 然科学版), 28, 286-289.]

Luo P, Zhou SL (2007). Effect of land use on ecological benefit of farm belt in suburbs. Journal of Ecology and Rural Environment, 23(4), 6-10. [罗培, 周申立 (2007). 土地利 用变化对城郊农业区生态效益的影响——四川省南 充市高坪区为例. 生态与农村环境学报, 23(4), 6-10.]

McGonigle TP, Miller MH, Evans DG, Fairchild GL, Swan JA (1990). A new method which gives an objective measure of colonization of roots by vesicular-arbuscular mycorrhizal fungi. New Phytologist, 115, 495-501.

Renner SS (2014). The relative and absolute frequencies of angiosperm sexual systems: Dioecy, monoecy, gynodioecy, and an updated online database. American Journal of Botany, 101, 1588-1596.

Rogers SR, Eppley SM (2012). Testing the interaction between inter-sexual competition and phosphorus availability in a dioecious grass. Botany, 90, 704-710.

Sharif M, Claassen N (2011). Action mechanisms of arbuscular mycorrhizal fungi in phosphorus uptake by Capsicum annuum L. Pedosphere, 21, 502-511.

Smith SE, Read DJ (2010). Mycorrhizal Symbiosis. Academic Press, London.

Smith SE, Smith FA, Jakobsen I (2003). Mycorrhizal fungi can dominate phosphate supply to plants irrespective of growth responses. Plant Physiology, 133, 16-20.

Song FQ (2002). Ecological and Physiological Research on VA Mycorrhizas of Populus ussuriensis. $\mathrm{PhD}$ dissertation, Northeast Forestry University, Harbin. [宋福强 (2002). 大青杨VA菌根生理生态学研究. 博士学位论文, 东北 林业大学, 哈尔滨.]

van der Heijden MGA, Boller T, Wiemken A, Sanders IR (1998). Different arbuscular mycorrhizal fungal species are potential determinants of plant community structure. Ecology, 79, 2082-2091.

Vierheilig H, Schweiger P, Brundrett M (2010). An overview of methods for the detection and observation of arbuscular mycorrhizal fungi in roots. Physiologia Plantarum, 125, 393-404.

Wang ZF, Xu X, Li XF, Yang P, Yuan XL (2011). The distribution of male and female Populus cathayana populations along an altitudinal gradient. Acta Ecologica Sinica, 31, 7067-7074. [王志峰, 胥晓, 李霄峰, 杨鹏, 袁新利 (2011). 青杨雌雄群体沿海拔梯度的分布特征. 生态学 报, 31, 7067-7074.]

Wu N, Li Z, Liu H, Tang M (2015). Influence of arbuscular mycorrhiza on photosynthesis and water status of Populus cathayana Rehder males and females under salt stress. Acta Physiologiae Plantarum, 37, 183. DOI: 10.1007/s11738-015-1932-6.

Wu N, Li Z, Wu F, Tang M (2016). Comparative photochemistry activity and antioxidant responses in male and female Populus cathayana cuttings inoculated with arbuscular mycorrhizal fungi under salt. Scientific Reports, 6, 37663. DOI: $10.1038 /$ srep37663.

Wu QP, Tang Y, Dong TF, Liao YM, Li DD, He XH, Xu X (2018). Additional AM fungi inoculation increase Populus cathayana intersexual competition. Frontiers in Plant Science, 9, 607. DOI:10.3389/fpls.2018.00607.

Wu QS, Yuan FY, Fei YJ, Li L, Huang YM, Liu CY (2014). Effects of arbuscular mycorrhizal fungi on root system architecture and sugar contents of white clover. Acta Prataculturae Sinica，23，199-204. [吴强盛，袁芳英，费永俊， 李莉, 黄咏明, 刘春艳 (2014). 从枝菌根真菌对白三叶 根系构型和糖含量的影响. 草业学报, 23, 199-204.]

$\mathrm{Xu} X$ (2016). Research advances in root recognition in plants. Journal of China West Normal University (Natural Sciences), 37, 365-369. [胥晓 (2016). 植物根系识别研究. 西华师范大学学报(自然科学版), 37, 365-369.]

Xu X, Peng G, Wu C, Korpelainen H, Li CY (2008). Drought inhibits photosynthetic capacity more in females than in males of Populus cathayana. Tree Physiology, 28, $1751-1759$.

Yang P, Xu X (2012). Effects of waterlogging stress on the growth and physiological characteristics of male and female Populus cathayana seedlings. Chinese Journal of Plant Ecology，36，81-87. [杨鹏, 胥晓 (2012). 淹水胁 迫对青杨雌雄幼苗生理特性和生长的影响. 植物生态 学报, 36, 81-87.]

Zeng Z (2016). Effect of Opposite Sexual Neighbor on the Root Growth, Component of Root Exudates of Female and Male Populus cathayana Rehd. Seedlings. Master degree dissertation, China West Normal University, Nanchong, Sichuan. [曾贞 (2016). 异性邻株对青杨雌雄植株根的生 长及其分泌物成分的影响. 硕士学位论文, 西华师范大 学, 四川南充.]

Zhang YM, Ma KM, Qu LY (2017). Inoculation with arbuscular mycorrhizal fungi enhances the root system of Bauhinia faberi var. microphylla seedlings under drought stress conditions. Acta Ecologica Sinica, 37, 2611-2619. [张亚敏, 马克明, 曲来叶 (2017). 干旱条件下接种AM 真菌对小马鞍羊蹄甲幼苗根系的影响. 生态学报, 37 , 2611-2619.]

www.plant-ecology.com 
Zhao QH, Sun LT, Wang Y, Ding ZT, Li M (2014). Effects of arbuscular mycorrhizal fungi and nitrogen regimes on plant growth, nutrient uptake and tea quality in Camellia sinensis (L.) O. Kuntze. Plant Physiology Journal, 50, 164-170. [赵青华, 孙立涛, 王玉, 丁兆堂, 李敏 (2014). 丛枝菌根真菌和施氮量对茶树生长、矿质元素 吸收与茶叶品质的影响. 植物生理学报, 50, 164-170.]

Zhao X, Yan XF (2006). Effects of arbuscular mycorrhizal fungi on the growth and absorption of nitrogen and phosphorus in Camptotheca acuminata seedlings. Journal of Plant Ecology (Chinese Version), 30, 947-953. [赵昕, 阎 秀峰 (2006). 丛枝菌根对喜树幼苗生长和氮、磷吸收的 影响. 植物生态学报, 30, 947-953.]

Zhu J, Liu G, Xiao J, Zhu SH, Zeng Z, Xu X, Dong TF (2016). Biomass of mulberry under planting modes of different gender combinations. Chinese Journal of Ecology, 35, 2336-2340. [朱娟, 刘刚, 肖娟, 竺诗慧, 曾贞, 胥晓, 董廷发 (2016). 桑树不同性别组合种植模式下的生物
量. 生态学杂志, 35, 2336-2340.]

Zhu SH, Dong TF, Liu G, Xiao J, Zhu J, Zeng Z, Chen DF, Xu $X$ (2016). Effects of root exudates on the growth and development of male and female Morus alba seedlings. Plant Physiology Journal, 52, 134-140. [竺诗慧, 董廷发, 刘 刚, 肖娟, 朱娟, 曾贞, 陈德甫, 胥晓 (2016). 桑树 (Morus alba)幼苗根系分泌物对雌雄植株生长发育的影 响. 植物生理学报, 52, 134-140.]

Zou YN, Wu QS, Li Y, Huang YM (2014). Effects of arbuscular mycorrhizal fungi on root system morphology and sucrose and glucose contents of Poncirus trifoliata. Chinese Journal of Applied Ecology, 25, 1125-1129. [邹英宁, 吴 强盛, 李艳, 黄咏明 (2014). 丛枝菌根真菌对枳根系形 态和蔗糖、葡萄糖含量的影响. 应用生态学报, 25 , 1125-1129.]

责任编委: 陈保冬 责任编辑: 李 敏 